Dino Milinović

University of Zagreb

dmilinov@ffzg.hr

ORCID: 0000-0003-4942-6937
Data przesłania tekstu do redakcji: 21.01.2019

Data przyjęcia tekstu do druku: 30.04.2019

\title{
Kasna antika: dekadencija ili „demokratizacija“" kulture?
}

Abstract: Milinović Dino, Kasna antika: dekadencija ili „,demokratizacija” kulture? (Late Antiquity: Decadence or "Democratization" of Culture?). "Poznańskie Studia Slawistyczne" 17. Poznań 2019. Publishing House of the Poznań Society for the Advancement of the Arts and Sciences, Adam Mickiewicz University, pp. 145-158. ISSN 2084-3011.

In our age "without the emperor", fascination with empires and with the emperor mystique continues. Take for witness Tolkien and his Return of the King, the third sequel of The Lord of the Rings, or the television serial Game of Thrones. In the background, of course, is the lingering memory of the decline and fall of the Roman Empire, "a revolution which is still felt by all nations of the world", to quote Edward Gibbon. It comes as a surprise that in this dramatic moment of its history, in times marked by political, economic and spiritual crisis that shook the very foundations of the Empire during the 3rd century, historians and art historians have recognized the revival of plebeian culture (arte plebea, kleinbürgerliche Kultur). It was the Italian historian Santo Mazzarino, talking at the XI International Congress of the Historical Sciences in Stockholm in 1960, who introduced a new paradigm: the "democratization of culture". In the light of the historical process in the late Roman Empire, when growing autocracy, bureaucracy, militarization and social tensions leave no doubt as to the real political character of the government, the new paradigm opened up fresh approaches to the phenomenon of decadence and decline of the Roman world. As such, it stands against traditional scenario of the "triumph of barbarism and Christianity", which was made responsible for the fall of the Roman Empire and the eclipse of the classical civilization of ancient Greece and Rome. It is not by accident that the new paradigm appeared around the middle of the 20th century, at the time when European society itself underwent a kind of "democratization of culture", faced with the phenomenon of mass culture and the need to find new ways of evaluating popular art. Today, more than anything else, the notion of "democratization of culture" in late Roman Empire forces us to acknowledge a disturbing correspondence between autocratic and populist forms of government. It may come as a shock to learn that the very emperors who went down in Roman history as villains and culprits (such as Caligula, Nero or Commodus), were sometimes considered the most "democratic" among Roman rulers. Do we need to feel certain unease at this historical parallel?

KEYwords: Roman Empire; Late Antiquity; Roman art; democratization of culture; decadence 
Period kasnoga Rimskog Carstva, poznat i kao „kasna antika“, po mnogočemu je zanimljivo i paradoksalno razdoblje. Za slikare i pjesnike s kraja 19. stoljeća to je vrijeme zasićenja, umora i dekadencije: „Sve smo pojeli, sve smo popili“, kaže Paul Verlaine u pjesmi Jadis et naguère, „Nije ostalo ništa više za reći. Samo ta dosada, niotkuda, koja nas je spopala“. Celestin Medović 1893. slika slavni Bakanal, historicističku viziju orgije pune vina i krvi (slika 1), koja može podsjetiti na Hollywood i biblijske spektakle tipa Ben Hur ili Deset zapovijedi. Za povjesničare to je kronika postupnog propadanja Rimskoga Carstva, ,revolucija koju i danas osjećaju svi narodi svijeta“, kaže Edward Gibbon u uvodu svoga utjecajnog djela (Gibbon, 1896-1900). Mistična aura cara i carstva proganjala je europsku povijest, od Karla Velikoga, preko Svetoga Rimskog Carstva, do Trećega Reicha. Razmišljajući o neophodnosti monarhije za dobrobit Italije i čitava svijeta, Dante citira Aristotela: „Bića ne žele biti loše upravljana; loše je pak mnoštvo vladarstava: jedan, dakle, neka bude vladar" $^{\text {"1 }}$ U ovo naše „doba bez careva, kako bi rekao Ernst Kantorowicz (rođen 1895. godine u Poznanju), fascinacija carstvom i carskom mistikom ne jenjava. Dovoljno je sjetiti se kultnog statusa Tolkienova Gospodara prstenova, odnosno, posljednjeg dijela trilogije, naslovljenoga Povratak kralja ili pak jednako globalno popularne Igre prijestolja, koja počiva na sličnim temeljima. Ali tema broja nije umjetnost carstva ili „,carska mistika“ u umjetnosti, već umjetnost i demokracija. Teško da bi itko pokušao tvrditi da je u vrijeme Rimskoga Carstva moguće govoriti o istinskoj demokraciji u političkome smislu, za razliku od moderne demokracije, pa čak i Atene Periklova doba ${ }^{2}$. Pa ipak, kasna antika je paradoksalno razdoblje; vjerojatno su zato generacije povjesničara i mislilaca uložile golem trud i mnogo vremena da rasvijetle ono što muči zapadnu povijest sve tamo od 476. godine, kada je barbarski vojskovođa Odoakar skinuo krunu s glave malog Romula Augustula i ostavio prijestolje Rimskoga Carstva praznim sve do Karla Velikog i onog Božića u Rimu 800. godine, kada je Zapad ponovo dobio cara. „Uskrsnuće“ carstva u liku Karla Velikog osiguralo je tomu nepismenom vladaru ključno mjesto u europskoj povijesti.

${ }^{1}$ Monarhija, I, X (Alighieri, 1976, 486).

${ }^{2} \mathrm{Za}$ usporedbu atenske i moderne demokracije v. Finley, 1976. 


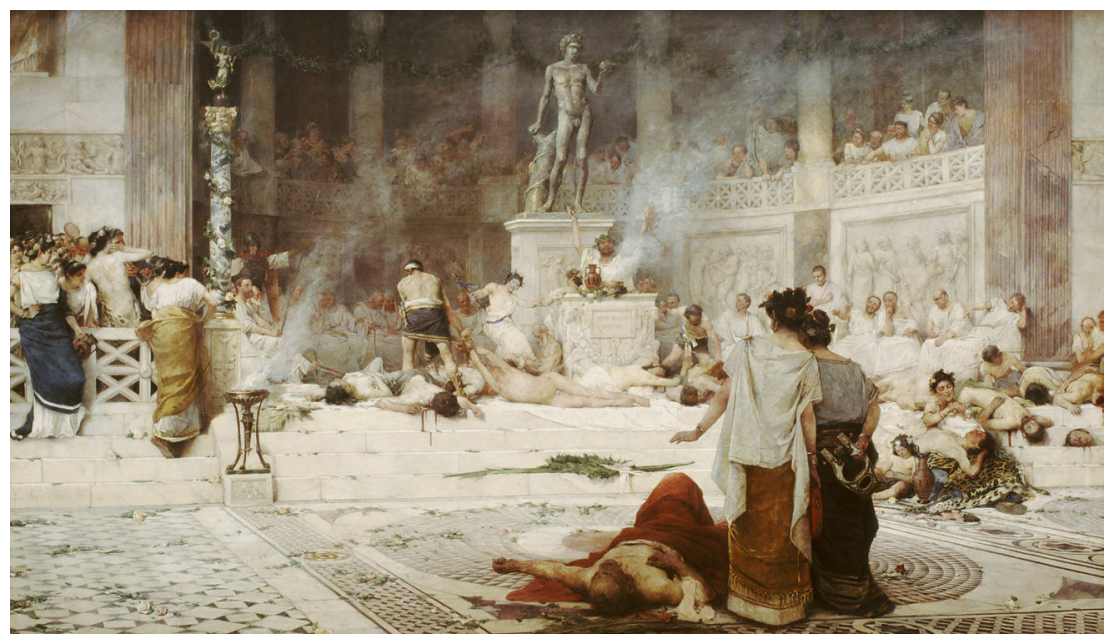

Slika 1. Celestin Medović, Bakanal, Moderna galerija, Zagreb

Nostalgija za Rimom nije, dakako, samo nostalgija za carstvom; Rimska Republika također je imala svoje poklonike kroz čitavu europsku povijest, pa je tako Cezarov ubojica Brut dobio jedno od svijetlih mjesta u galeriji književnih junaka: „Tko je ovdje tako kukavan da bi htio biti rob? Tko je ovdje tako divljačan da ne bi htio biti Rimljanin? Tko je ovdje tako podao, da ne voli svoju zemlju? ${ }^{\text {‘3 }}$. Saint-Juste, jedan od vođa Francuske revolucije, u revolucionarnom će zanosu uskliknuti: „Sve od nestanka Rima svijet je bio prazan“ (Vidal-Naquet, 1976, 19). Republika ili carstvo, Rim je s vremenom postao paradigma uspona i pada, model za proučavanje. „Potrošena stvar“, reći će Voltaire, ali Montesquieu i njegova „Razmišljanja o uzrocima veličine i dekadencije Rimljana“ iz 1734. godine do danas ostaju klasik prosvjetiteljske političke historiografije, na kojemu će Edward Gibbon izgraditi svoj monumentalni opus. Povijest Carstva je učiteljica i poslužit će kao putokaz osnivateljima (Founding Fathers) Sjedinjenih Američkih Država. Alexis de Tocqueville u svojoj knjizi Demokracija u Americi objašnjava zašto je bavljenje poviješću Rima važno za zdrav razvoj mlade američke demokracije: „Nedostatak takvog interesa

${ }^{3}$ Julije Cezar, III, 2 (Shakespeare, 1981). 
predstavlja prijetnju iznutra cjelovitosti i budućnosti američke civilizacije [...]. Budući da je Rimsko Carstvo propalo uslijed barbarskih invazija, danas smo možda odveć skloni misliti da je to jedini način na koji jedna civilizacija može nestati“ (Tocqueville, 1954, 48). Ovdje nije mjesto za raspravu o propasti Rimskoga Carstva; samo želim podsjetiti na ogromno historiografsko nasljeđe koje zauzima velik dio prostora u našim knjižnicama, ali i na obilje spomenika, književnih i likovnih djela koji nas svakodnevno podsjećaju na Rim.

Umjetnost i demokracije, dakle. Vrijeme o kojem želim govoriti je razdoblje između vladavine cara Marka Aurelija i Konstantina (zvanog Veliki), otprilike od druge polovice drugoga, pa do prve trećine 4. stoljeća. To je razdoblje kojim dominira velika kriza Carstva, kada je „materijalno nazadovanje najintenzivnije, a fermentacija novih religijskih osjećaja u punom jeku“ antički svijet toga vremena je ,intelektualno osiromašen, materijalno nesiguran, ispunjen strahom i mržnjom“ (Dodds, 1965, 3). Riječi su to Erica Doddsa iz 1965. godine, u knjizi čiji naziv će ostati upamćen kao jedan od popularnih sinonima za kasnu antiku: The Age of Anxiety. Doba tjeskobe. Sud britanskoga povjesničara Mosesa I. Finleya, obilježen autorovim izrazito marksističkim svjetonazorom, još je zlokobniji: „Taj je svijet bio lišen slobode, kreativnosti i nade: ljudi su očekivali spas na nebu, ne na zemlji. Bio je to svijet masovnog ropstva, s nepojmljivo bogatim pojedincima, svijet neznanja i strahovitog praznovjerja“ (Finley, 1989, 155). Niz osuda je dugačak; spomenimo još Ramsaya MacMullena, za koga se društvo kasnoga Carstva sastoji „od onih na vrhu i - svih ostalih“ (MacMullen, 2003, 467). Daleko smo od ideala antičkoga polisa, daleko od atenske demokracije; doista, razlika je i više nego očita usporedimo li prikaz atenskih građana u Panatenejskoj povorci s Partenona iz 5. st. pr. Kr. (slika 2) i detalj Konstantinova friza na slavoluku iz 315. godine u Rimu (slika 3), gdje je car prikazan kako okupljenim senatorima i građanima dijeli darove u novcu (largitio). Dok su Atenjani Periklova doba prikazani kao ravnopravni sudionici u povorci, dotle je na rimskome reljefu Konstantin u središtu simetrične kompozicije, prikazan frontalno i veći od ostalih sudionika. Slično je i prikaz cara na postolju Teodozijeva obeliska u Konstantinopolu s kraja 


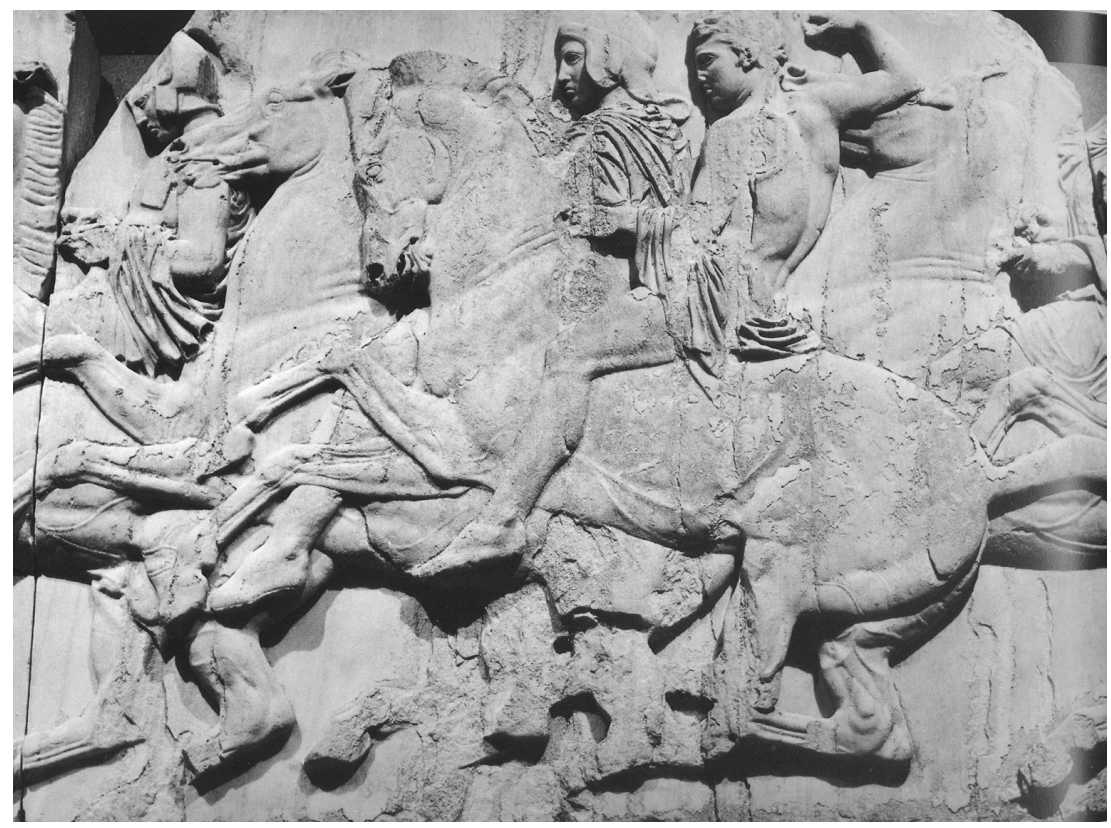

Slika 2. Friz Panatenejske povorke s Partenona u Ateni, British Museum, London (prema: Boardman, J. i Finn, D., The Parthenon and its Sculptures, London, 1985)

4. stoljeća organiziran prema principu „okomite osi aklamacije“, s carem u vrhu (slika 4). To čak više nije onaj principat koji je ustanovio August (primus inter pares) ni „liberalno“ carstvo iz vremena jednog Vespazijana, koji se znao našaliti da novac nema mirisa kada su ga kritizirali što ubire porez na javne zahode u Rimu; u promijenjenim obrascima vladanja mnogi prepoznaju karakteristike orijentalnog despotizma, prisutnog u ceremonijama, dvorskoj etiketi, odjeći i reprezentaciji, kao i u nazivu „gospodar“ (dominus), koji među prvima koristi Dioklecijan. Kako, dakle, govoriti o „demokratizaciji kulture“ u takvu političkom okruženju?

Valja reći da je povijest umjetnosti krajem 19. stoljeća napravila vjerojatno odlučujući iskorak u drugačijem vrednovanju završnoga dijela antičke civilizacije, odnosno kasne antike. Zapravo, nije pogrešno reći da je moderna disciplina povijesti umjetnosti praktički nastala u tom procesu; Alois Riegl, jedan od vodećih predstavnika Bečke škole prvi je uspostavio 


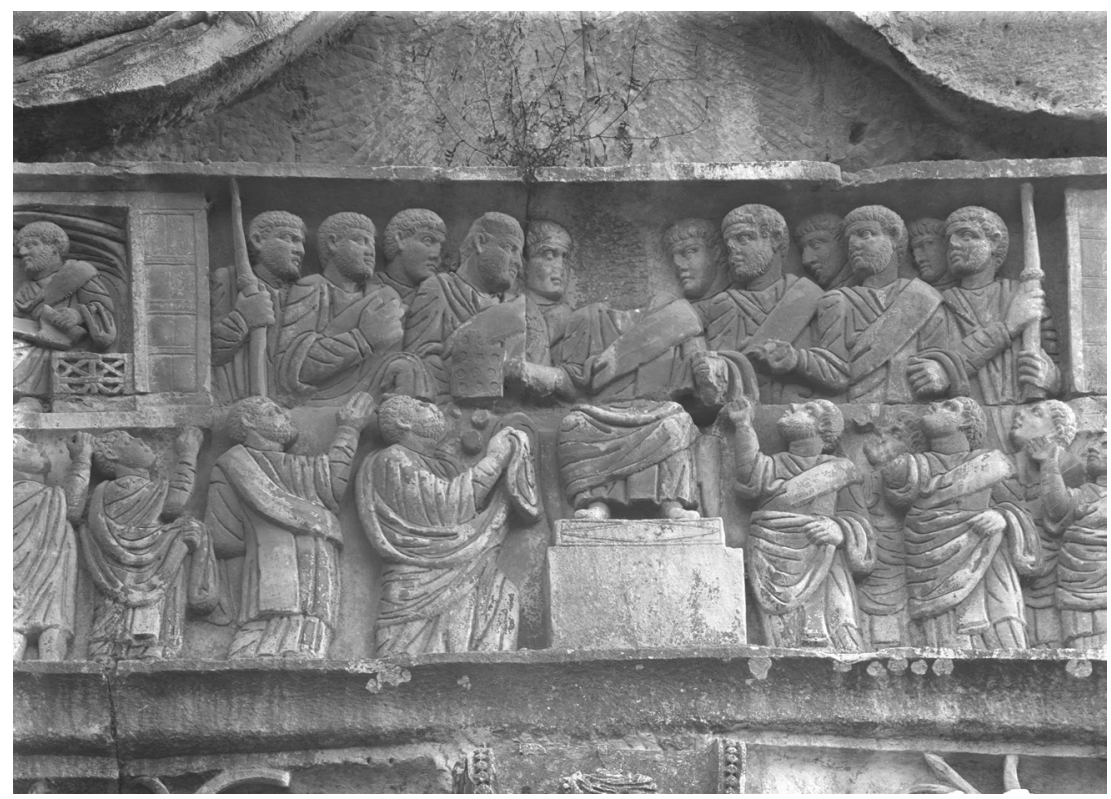

Slika 3. Friz s Konstantinovog slavoluka u Rimu (foto: G. von Kaschnitz, DAI Rom, 31.2069)

drugačije kriterije za proučavanje kasnoantičke umjetnosti. Njegov pojam „umjetničkog htijenja“ (Kunstwollen), zamijenio je kategorije razvitka i nazadovanja (dekadencije) u umjetnosti, odnosno dotadašnje shvaćanje prema kojemu se umjetnost dijelila na elitna i manje vrijedna razdoblja te na „visoku“ i ,primijenjenu“ umjetnost. Možemo reći da se s Rieglom dogodila ,demokratizacija“ ne samo ornamenta u umjetnosti (Stilfragen iz 1893. godine) ili pučke umjetnosti (Volkskunst iz 1894.) već i same discipline povijesti umjetnosti, iz čega su proizašle i neke sasvim nove stilske kategorije, kao što su kasna antika ili manirizam. „Dobar ukus“, koji je Johann Joachim Winckelmann čvrsto vezao uz klasične kanone u antičkoj umjetnosti, sada više nije bio ograničen na pojedina razdoblja, a pojmu umjetnosti vraćen je univerzalni smisao likovnoga govora, ovisnog prije svega o formi (Winckelmann, 1991, 15). Ipak, niti Riegl nije mogao pobjeći od utjecaja povijesnih okolnosti na promjene u umjetnosti; kada govori o „svođenju svega na istu ravninu“ (Absolute Nievellierung), kao 


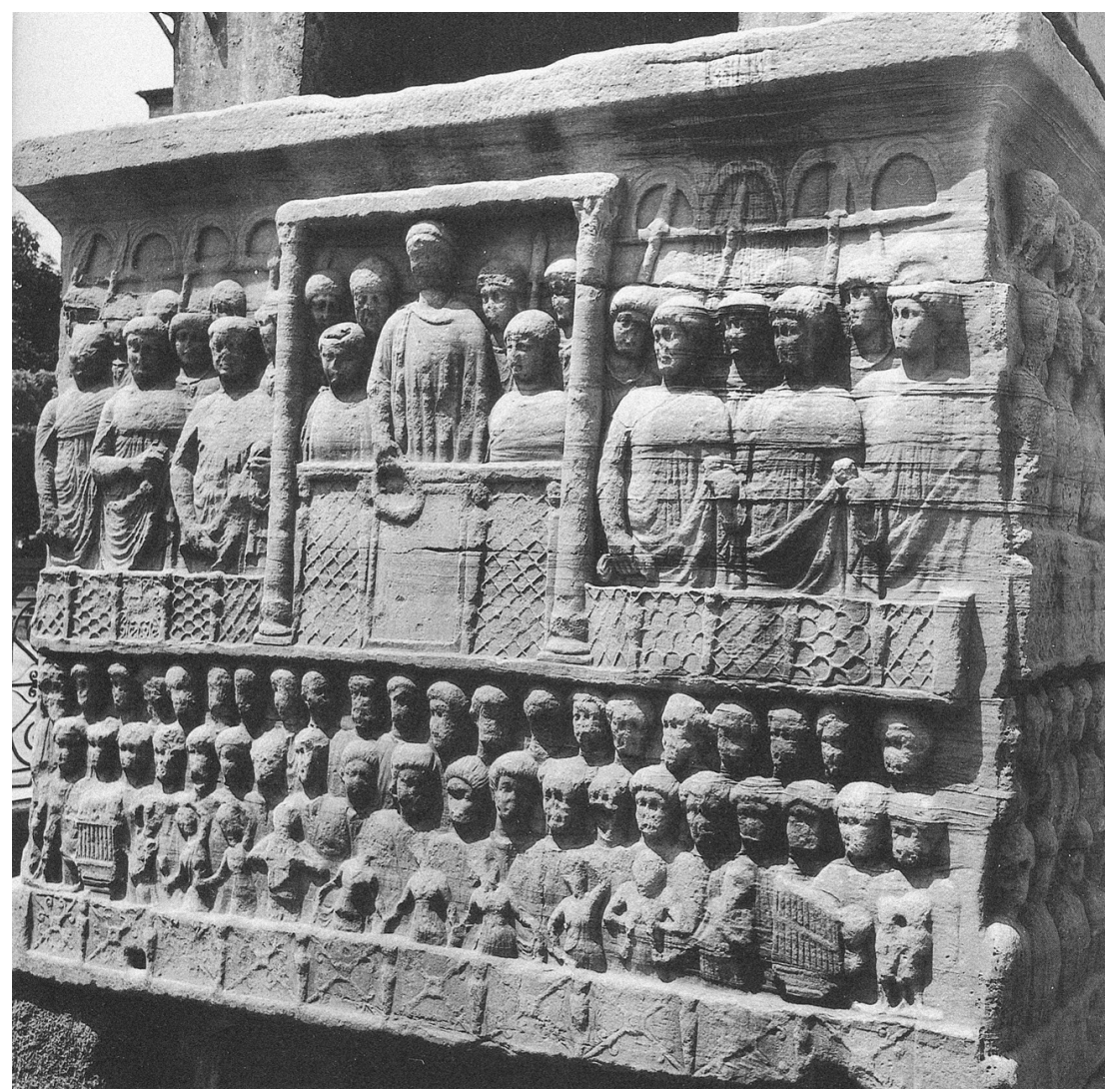

Slika 4. Postolje Teodozijeva obeliska u Istanbulu (foto: Sender, 1925, DAI Istanbul, KB25.775)

prepoznatljivome optičkom obilježju postklasične, ili antiklasične umjetnosti, tada tu pojavu uspoređuje sa socijalnim tendencijama u ranome kršćanstvu, pri čemu nije teško zaključiti da formativni aspekt likovnoga procesa odgovara „demokratizaciji“ društva, odnosno kršćanskom pogledu na svijet (Weltanschauung). Taj je nakon 313. godine (Milanski edikt) postupno zamijenio ,pravo jačega“ (das Recht des Stärkeren) ranijega politeističkog razdoblja (Riegl, 1966, 103)4.

${ }^{4} \mathrm{O}$ društvenoj komponenti u Rieglovoj teoriji v. Caillet (2001). 
Riegl je otvorio vrata novim tumačenjima u umjetnosti kasne antike. Nakon njega brojni su se povjesničari umjetnosti vraćali traženju odgovora na pitanje kako objasniti promjene koje su se dogodile u vremenu između Marka Aurelija i Konstantina. Josef Strzygowski tražio im je korijene u orijentalnim tradicijama i podrivajućem utjecaju Bliskoga istoka na Rim, Juvenalovu „mulju“ što ga je sirijska rijeka Oront naplavila sve do Tibera 5 . Drugi su se u većoj mjeri oslanjali na ekonomsku povijest, potaknuti knjigom Michaela Rostovtzefa (Social and Economic History of the Roman Empire) iz 1926. godine. Gerdt Rodenwaldt „stilski zaokret“ (Stilwandel) u antičkoj umjetnosti dovodi u vezu sa žilavošću rimske ,pučke“ likovne tradicije (Volkskunst); za razliku od klasičnoga, taj je stil ,životan i ima budućnost“ (Rodenwaldt, 1940, 42). Karl von Schönebeck govori o „malograđanskoj zagrobnoj kulturi“ (kleinbürgerliche Grabeskultur) na sarkofazima s početka 4. stoljeća (Schönebeck, 1936); Ranuccio Bianchi-Bandinelli, na Rodenwaldtovu tragu, o ,plebejskoj umjetnosti“ (arte plebea) (Bianchi Bandinelli, 1969). Naposljetku, na XI. međunarodnom kongresu povijesnih znanosti u Stockholmu 1960. godine talijanski povjesničar Santo Mazzarino iznosi svoje argumente u prilog ,demokratizaciji kulture u kasnome Carstvu“ (Mazzarino, 1960).

Teško je ukratko objasniti suštinu pojma „demokratizacije“; on predstavlja ,područje znanstvenog istraživanja čije su konture podložne stalnim promjenama“ (Carrié, 2001, 28), što podrazumijeva da tumačenja u različitim područjima (disciplinama) mogu poprimiti bitno drugačija obilježja. Za povjesničara Mazzarina naglasak je na procesu deromanizacije i buđenja „nacionalnih“ kultura u njihovim vjerskim i jezičnim aspektima, što se događa usporedo sa širenjem kršćanstva ${ }^{6}$. Bianchi Bandinelli vidi ,,plebejsku umjetnost" kao plod autentične, srednjeitalske likovne tradicije, koja traje ispod mramornoga sjaja Augustova klasičnog Rima da bi u kasnijim stoljećima izbila na površinu i zauzela mjesto i na carskim, javnim spomenicima (cf. Bianchi Bandinelli, 1969, 281). To je, dakako, ostvarivo samo uslijed postupnog slabljenja utjecaja koji klasična kultura kao civilizacijski model ima u elitnim krugovima Rima. Jačanje ,plebejske“ struje tako

${ }^{5} \mathrm{O}$ usporednom putu dvojice bečkih povjesničara umjetnosti v. Elsner (2002).

${ }^{6} \mathrm{Za}$ MacMullena $(2003,477)$ termin ima više zemljopisne, a manje društvene implikacije („His key term has a different meaning from the more obvious and familiar one: it is geographical more than social"). 
je prije svega posljedica pucanja tradicionalnog ustroja Carstva koje je počivalo na osjetljivoj ravnoteži između ovlasti imperatora i uloge senatske aristokracije u održavanju drevnih mehanizama rimskoga društva. U tom smislu promjene prate novu distribuciju moći u državi, ali teško je govoriti o „demokratizaciji“ u političkom smislu; to je vrijeme kada buja birokracija s jedne te vojnička aristokracija s druge strane. Na ta dva stupa počiva upravna struktura kasnoga Rimskoga Carstva. Takva politička i društvena evolucija nameće promjene u tradicionalnoj ikonografiji moći i prilagodbu ranijih tipova „reprezentacijskih slika“ novim uvjetima. Te promjene dolaze do izražaja na Konstantinovu slavoluku iz 315. godine, na kojemu je ideja obnovljenog carstva popraćena nizanjem carskih reljefa - spolija iz vremena Trajana, Hadrijana i Marka Aurelija. Oni predstavljaju sintezu carske povijesti i odskočnu dasku za jedno novo razdoblje - to je božanska monarhija u nastajanju, na čelu s Božjim namjesnikom. Takva monarhija, upozorava Peter Brown, nije other-wordly, ona je upper-wordly (Brown, 1978, 16).

Kako shvatiti paradoks „demokratizacije kulture“ u društvu takvih političkih ambicija? Možda je ključ u kršćanstvu, odnosno Euzebiju i njegovu hvalospjevu Konstantinu, u kojemu Peter Brown vidi pokušaj biskupa iz Cezareje da predstavi karijeru uspješnog autokrata kao model pobožna života, most između vladara i svetca, između svjetovne i duhovne vlasti (Brown, 1978, 14)7. O tome svjedoči sam Konstantin, koji sebe naziva „biskupom onih izvan Crkve“. Ali takvi će pokušaji brzo, već za njegovih nasljednika, završiti u cezaropapizmu, a ne u demokratičnijem društvu ranih kršćanskih zajednica, jednako kao što će „okomita os aklamacije“, kakva je prisutna na postolju Teodozijeva obeliska (vidi sliku 4), brzo postati uzor za prikaze Krista u slavi u kršćanskoj umjetnosti. Što, dakle, možemo navesti u prilog ,demokratizaciji kulture“ u kasnoantičkoj umjetnosti ako to nije puko izjednačavanje stilskih promjena sa ,svođenjem na istu ravninu“, metamorfoza taktilne u „optičku“ formu, kako taj proces tumači Riegl? Koje su to odlike - formalne i ikonografske - koje su u tom smislu indikativne, a koje nisu prisutne u ranijoj helenističko-rimskoj umjetnosti? Za pristaše klasičnoga „kanona“ ta je umjetnost deformirana kao u slučaju

${ }^{7}$ Brown se osvrće na teškoće koje moderni povjesničari imaju s interpretacijom Euzebijeva djela i njegova „cilja“; (v., primjerice, Momigliano 1963). 


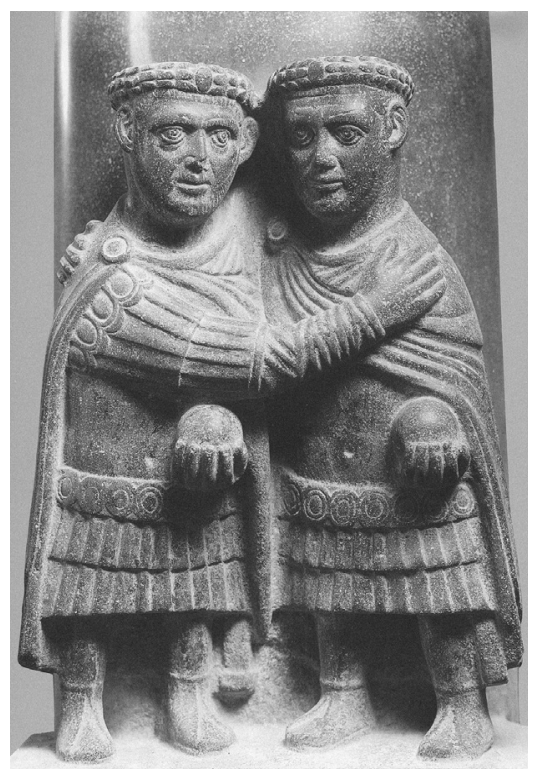

Slika 5. Dva tetrarha, Biblioteca Apostolica Vaticana (foto: C. Faraglia, DAI Rom, 5694)

ovih „portreta“ Dioklecijana i njegovih tetrarha s kraja 3. stoljeća (slika 5), koje Hans Peter L'Orange naziva Schreckbilder, ukazujući na njihov potencijal da izazovu strah i poslušnost (L'Orange, 1984). Gubitak fizionomijske sličnosti (zbog čega je nemoguće razlikovati Dioklecijana od Maksimijana, dok su dvojica mlađih tetrarha prepoznatljivi po nedostatku brade), anatomske preciznosti u prikazu tijela $i$, umjesto toga, naglasak na gesti zagrljaja, koja ukazuje na pravi sadržaj poruke - jedinstvo i slogu vladajućih tetrarha - sve to su novine u likovnom izričaju, u službi novoga poretka. Treba li uopće spominjati da je takva likovna proizvodnja anonimna, da su nestala imena majstora koji su se još do nedavna potpisivali na svoje radove (najčešće kopije grčkih djela)? Ili da su nestali sustavni pregledi umjetničke baštine poput onih koje je Plinije Stariji uvrstio u svoje Prirodoslovlje ( $\mathrm{Na}$ turalis historia), opisi poput Pauzanijinog Vodiča po Heladi (Periegesis)? Amijan Marcelin, povjesničar s kraja 4. stoljeća, od umjetnika spominje jedino Fidiju i Praksitela, ali njihova su imena samo pokazatelj jedne ,antikvarske kulture" koja se grčevito drži uzora iz prošlosti ${ }^{8}$.

To je i vrijeme postupnoga nestanka pune plastike, najslavnijeg izdanka klasične umjetnosti. Umjesto toga, povećan je interes za šaroliko i dekorativno. Novi se ukus odražava u većoj prisutnosti materijala i tehnika kao što su polikromni mozaik, opus sectile, srebro, bjelokost. Ni jedan od tih nije dostupan širim društvenim krugovima; srebro i bjelokost u 4. stoljeću

${ }^{8}$ Dobar prikaz, antikvarskog“ mentaliteta u kasnome Carstvu u: Elsner, (1998, posebno 169 i dalje). 
dobivaju ceremonijalnu namjenu koja nadilazi njihovu sporadičnu pojavu u ranijim stoljećima. Naposljetku, to je vrijeme intenzivnog razvoja „dekora koji okružuje smrt", potaknutog sve većim zanimanjem za zagrobni život i promjenom tradicionalnih običaja (ukapanje umjesto spaljivanja) ${ }^{9}$. Nova religioznost, koja je obilježila prva stoljeća Carstva i pripremila tlo za trijumf kršćanstva, dala je poticaj razvoju umjetnosti u kontekstu groba. Taj je dekor oduvijek bio važan u rimskome društvu ${ }^{10}$, ali nikada prije tako likovno raznovrstan i ambiciozan. Bogati korpus sarkofaga i nadgrobnih spomenika predstavlja vjerojatno najzanimljiviji dio umjetničke proizvodnje između 2. i 4. stoljeća; kada Peter Brown kaže da su ,zahtjevi ljudskih bića" (the claims of human beings) ono što kasnoj antici daje njezino prepoznatljivo obilježje (Brown, 1978, 16), tada moramo pomisliti na realističnu struju u rimskoj zagrobnoj umjetnosti koja utjelovljuje te glasove (slika 6). Stoga možda jedino na području zagrobne umjetnosti možemo govoriti

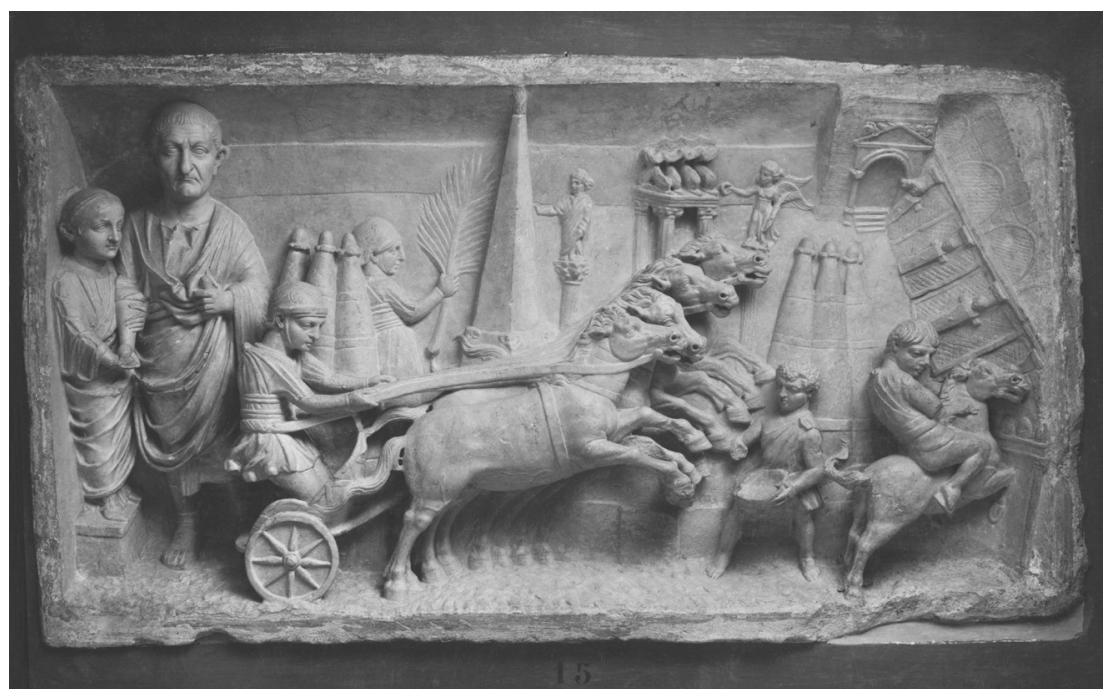

Slika 6. Nadgrobni reljef iz Ostije, Musei Vaticani (foto: C. Faraglia, DAI Rom, 39.557R)

${ }^{9}$ Za pregled takvih običaja v., primjerice, Toynbee (1971).

${ }^{10}$ Iz njega, uostalom, dolazi običaj pravljenja posmrtnih maski, odnosno, fenomen rimskog realističnog portreta. 
o „demokratizaciji“ u smislu afirmacije šire palete ljudskog iskustva. Nije stoga čudno da su gore spomenuti povjesničari umjetnosti (Rodenwaldt, Schönebeck, Bianchi Bandinelli) upravo u privatnom kontekstu „dekora koji okružuje smrt" pronašli rane primjere novoga stilskog izričaja, koji će kasnije prodrijeti i u službenu umjetnost. Kršćanska će umjetnost dobrim dijelom preuzeti repertoar tradicionalne zagrobne umjetnosti, pridodajući postupno priče iz Staroga i Novoga zavjeta; zanimljivo je, međutim, da razdoblje bogatoga zagrobnog dekora traje relativno kratko i da se već prema kraju 4. stoljeća gase radionice sarkofaga, dok su zidni oslici u katakombama nestali i ranije. Teško je objasniti razloge za polako „klizanje prema tišini i anonimnosti groba“ (Février, 1983, 46) ${ }^{11}$, ali to je ujedno i kraj jednog specifičnog likovnog repertoara koji je mogao dati povoda za razgovor o fenomenu ,demokratizacije“ u umjetnosti kasne antike.

Da zaključim, premda smo samo odškrinuli vrata problema. „Demokratizacija kulture" svojevremeno se pojavila kao odgovor na katastrofičnu historiografsku tradiciju koja u kasnoj antici vidi „trijumf barbarstva i kršćanstva“. Promjene o kojima govore, svaki na svome području, Riegl i Santo Mazzarino ili poslije njih Peter Brown - ukidanje razlika između elitne i vulgarne kulture, glas maloga čovjeka s ulice koji je prisutan u djelima kršćanskih autora, neočekivana društvena mobilnost - sve idu u prilog pozitivnog shvaćanja povijesnoga procesa i dadu se upisati u tendencije tipične za historiografiju „kulturnog zaokreta“ (Cameron, 2004). Još do jučer mogli smo se lako s njima poistovjetiti, suočeni s potrebom vrednovanja popularne kulture u drugoj polovici 20. stoljeća. Za druge, međutim, ista je pojava katastrofičan scenarij, nivelizacija (na niže) ili vulgarizacija, koju obilježavaju gore navedeni stilski parametri, poistovjećeni s propadanjem klasične kulture i antičkoga svijeta (više o tome u Milinović, 2016, 13-24). Budući da danas na oba pristupa možemo gledati iz veće ili manje povijesne udaljenosti, možda bismo morali postaviti pitanje je li moguće prepoznati sličnosti između kasnoantičke „demokratizacije kulture“ i suvremenih tendencija, primjerice, s posljedicama sve prisutnijeg populizma u politici, svojevrsnog novog političkog kiča koji se želi nametnuti i kroz kulturu. Još je 1936. godine Walter Benjamin ustvrdio da je „masa matrica po kojoj se danas preobražavaju svi uvriježeni stavovi prema umjetničkim

\footnotetext{
${ }^{11}$ Février: „Ce glissement vers le silence et l'anonymat de la tombe“.
} 
djelima. Kvantitet se preobraća u kvalitet“ (Benjamin, 1968, 28). Može zvučati neobično, pa čak i šokantno, ali carevi koji su u rimskoj povijesti ostali zabilježeni kao „ludi““ (Kaligula, Neron, Komod, Elgabal ili Galijen), doživjevši „,brisanje iz sjećanja“ (damnatio memoriae), katkad se navode i kao „najdemokratskiji“; pritom „demokratičnost“ nemamo razloga shvatiti drugačije nego kao neprijateljstvo prema tradicionalnim rimskim elitama i kupovanje naklonosti običnoga puka u vidu besplatnoga kruha, vina, svinjetine i zabave. Venari, lavari, ludere, ridere, hoc est vivere (Lov, kupatilo, igre, smijeh, to je život), čitamo na jednom epitafu iz 3. stoljeća. U tom pogledu kasna antika predstavlja vrhunac civilizacije spektakla; sredinom 4. stoljeća građanin Rima imao je osiguranu besplatnu zabavu u cirkusu ili amfiteatru tijekom dvije trećine godine. Cirkus i amfiteatar su mjesta zabave, ali i iluzije, gdje rimski puk smije izazivati sebi nadređene, pa čak i cara, kao da je on i dalje samo jedan od njih, primus inter pares. Je li taj najočigledniji privid „demokratizacije kulture“ $u$ kasnoj antici i danas isti varljivi privid demokratičnosti?! „Fašizam [...] svoj spas vidi u tome da masama dopusti da dođu do svoga izraza, nikako do svoga prava“" (Benjamin, 1968, 29). Trebamo li osjetiti nelagodu na takvu povijesnu usporedbu?

\section{Literatura}

Alighieri, D. (1976). Monarhija. Prev. T. Maroević i M. Tomasović. U: D. Alighieri, Djela. Sv. I. Zagreb: Sveučililšna naklada Liber - Nakladni zavod Matice hrvatske. Benjamin, W. (1968). Umjetničko djelo u doba svoje tehničke reproduktivnosti. Prev. S. Knežević. ,Život umjetnosti““ br. 6, str. 22-32.

Bianchi Bandinelli, R. (1969). Rome, le centre du pouvoir. Paris: Gallimard.

Brown, P. (1978). The Making of Late Antiquity. Cambridge - London: Harvard University Press.

Caillet, J.-P. (2001). Alois Riegl et le fait social dans l'art de l'antiquité tardive. „Antiquité tardive" br. 9, str. 47-51.

Cameron, A. (2004). History and the Individuality of the Historian: the Interpretation of Late Antiquity. U: The Past Before Us. The Challenge of Historiographies of Late Antiquity. Ed. C. Straw and R. Lim. „Smith Studies in History Series“ 54. Turnhout: Brepols, str. 69-78.

Carrié, J.-M. (2001). Antiquité tardive et ,, démocratisation de la culture “: un paradigme à géométrie variable. „Antiquité tardive“ br. 9, str. 27-46. 
Dodds, E. R. (1965). Pagan \& Christian in an Age of Anxiety. New York - London: W. W. Norton \& Company.

Elsner, J. (1998). Imperial Rome and Christian Triumph: the art of the Roman Empire $A D$ 100-450. Oxford - New York: Oxford University Press.

Elsner, J. (2002). The Birth of Late Antiquity: Riegl and Strzygowski in 1901. „Art History" vol. 25, no. 3, str. 358-379.

Février, P.-A. (1983). Une approche de la conversion des élites au IVe siècle: le décor de la mort. „Miscellanea historiae ecclesiasticae“ VI (Congrès de Varsovie, 1978). Wrocław - Bruxelles: Ossolineum, str. 22-46.

Finley, M. I. (1976). Démocratie antique et démocratie moderne. Paris: Éditions Payot. Finley, M. I. (1989). On a perdu la guerre de Troie. Propos et polémiques sur l'Antiquité. Paris: Les belles lettres.

Gibbon, E. (1896-1900). The History of the Decline and Fall of the Roman Empire. Ed. J. Bury. London: Methuen.

L'Orange, H. P. (1984). Das spätantike Herrscherbild von Diokletian bis zu den Konstantin-Sohnen. Berlin: Gebrüder Mann Verlag.

MacMullen, R. (2003). Cultural and Political Changes in the 4th and 5th Centuries. „Historia: Zeitschrift für Alte Geschichte“ vol. 52, no. 4, str. 465-495.

Mazzarino, S. (1960). La democratizzatione della cultura nel 'basso impero'. „XIe Congrès international des sciences historiques (Stockholm, 1960). Rapports" vol. 2: Antiquité. Göteborg - Stockholm - Upsala: Almqvist et Wiskell, str. 35-54.

Milinović, D. (2016). Nova post vetera coepit. Ikonografija prve kršćanske umjetnosti. Zagreb: FF Press i Hrvatska sveučilišna naklada.

Momigliano, A. D. (1963). Pagan and Christian Historiography in the Fourth Century A.D. In: The Conflict between Paganism and Christianity in the Fourth Century. Oxford: Clarendon Press, pp. 79-99.

Riegl, A. (1966). Historische Grammatik der bildenden Künste. Hrsg. O. Pächt, K. M. Swoboda. Darmstadt: Böhlaus.

Rodenwaldt, G. (1940). Römische Reliefs. Vorstufen zur Spätantike. „Jahrbuch des Deutschen archaeologischen Instituts“ no. 55, str. 11-43.

Schönebeck, K. von (1936). Die altchristliche Sarkophagplastik unter Konstantin. „Römische Mitteilungen“ no. 51, str. 239-336

Shakespeare, W. (1981). Julije Cezar. Prev. M. Maras. Zagreb: Nakladni zavod Matice hrvatske.

Tocqueville, A. de (1954). Democracy in America. Vol. 2. New York: Vintage Books.

Toynbee, J. M. C. (1971). Death and Burial in the Roman World. London: Thames and Hudson.

Vidal-Naquet, P. (1976). Tradition de la démocratie grecque. U: M. I. Finley. Démocratie antique et démocratie moderne. Paris: Éditions Payot.

Winckelmann, J. J. (1991). Réflexions sur l'imitation des oeuvres grecques en peinture et en sculpture. (Izvorno: Gedanken über die Nachahmung der griechischen Werke in der Malerei und Bildhauerkunst [1755]). Trad. M. Charrière. Nîmes: Éditions Jacqueline Chambon. 